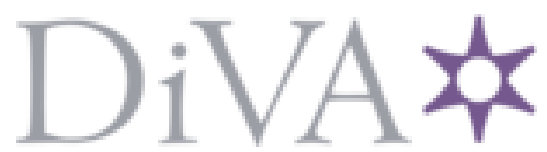

http://www.diva-portal.org

\title{
Postprint
}

This is the accepted version of a paper published in European Journal of Oncology Nursing. This paper has been peer-reviewed but does not include the final publisher proof-corrections or journal pagination.

Citation for the original published paper (version of record):

Björklund, M., Fridlund, B., Mårtensson, J. (2019)

Experiences of psychological flow as described by people diagnosed with and treated for head and neck cancer

European Journal of Oncology Nursing, 43: 101671

https://doi.org/10.1016/j.ejon.2019.09.012

Access to the published version may require subscription.

N.B. When citing this work, cite the original published paper.

Permanent link to this version:

http://urn.kb.se/resolve?urn=urn:nbn:se:hj:diva-46677 


\section{Experiences of psychological flow as described by people diagnosed with and treated for head and neck cancer}

Margereth Björklund ${ }^{\mathrm{a}}$, Senior Lecturer, PHD, RN

Bengt Fridlund $^{\mathrm{b}}$, Senior Professor, PhD, RNT

Jan Mårtensson ${ }^{\mathrm{a}}$, Professor, PhD, RN

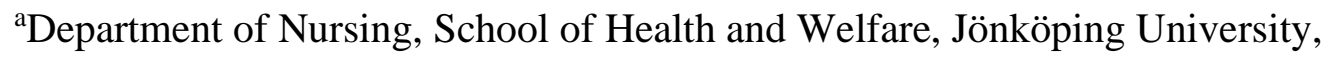
SE-551 11 Jönköping, Sweden

${ }^{\mathrm{b} C I C E}$, Linnaeus University, SE-351 95 Växjö, Sweden

Correspondence to: Margereth Björklund, PHD, RNT, Senior Lecturer, Department of Nursing, School of Health and Welfare, Jönköping University, P.O. Box 1026, SE-551 11 Jönköping, Sweden

Telephone +46702763318

E-mail: margereth.bjorklund@ju.se

margerethb@gmail.com 


\section{Abstract}

Purpose: To describe flow as experienced by people diagnosed with and treated for head and neck cancer.

Method: A descriptive design based on a deductive qualitative content analysis was used to explain Csikszentmihalyi's flow theory from the perspective of people living with head and neck cancer. Interviews were conducted with seven participants diagnosed with and treated for different forms and stages of head and neck cancer.

Results: Experiences of flow were associated with people's interests, skill levels and actions involving and creating both happiness and the feeling of something worth living for. Optimal flow was a state of consciousness in which mind and body work together, and the people were completely absorbed in an activity related to nature, hobbies or family. Microflow occurred as part of everyday life, relieving stress and anxiety and helping them to focus on their daily routines. This included humming, listening to the radio or watching TV.

Conclusions: The people's inner strength and desire to feel better made flow possible, and they used unknown skills that enhanced self-satisfaction. Managing self-care activities increased feelings of control, participation and enjoyment. This calls for person-centred care with a salutogenic approach based on the people's own interests, skill levels and actions; what makes the person feel happy.

Keywords: empowerment; flow theory; happiness; head and neck cancer; life experiences; person-centred care; qualitative content analysis; salutogenic approach 


\section{Highlights}

What is already known about experiences of flow described by people diagnosed with and treated for head and neck cancer?

- A pathogenic approach only focusing on disease and problems often results in an incomplete understanding of a person's condition, e.g. when having head and neck cancer

- Flow theory is a practice of positive psychology and moves beyond the disease and supports the person's growth, providing conditions to balance problem-focused care when having, e.g. breast cancer

- This salutogenic approach concentrates on a person's strength and health resources and has shown to be a significant factor on a feeling of well-being and happiness when having, e.g. breast cancer

- No study has been found describing flow theory in a head and neck cancer context.

What this paper adds about experiences of flow described by people diagnosed with and treated for head and neck cancer?

- The participants with head and neck cancer use attentive focus, feedback, inner strength, control and a desire to feel better that makes flow experiences possible

- Optimal flow is a state of consciousness in which mind and body works together and the participants with head and neck cancer use unknown skills that enhance selfsatisfaction and feelings of happiness

- It is important for people with head and neck cancer to retrain habits and day-to-day activities since microflow occur as part of everyday life in order to relieve stress and anxiety

- It is important to identify and establish care routines in order to support people with head and neck cancer and a person-centred care. This salutogenic approach increases experiences of flow and enhances feelings of control, participation, self-care activities and enjoyment. 


\section{Introduction}

It is well known that people with head and neck cancer (HNC) report many disease and health-related problems before, during and a long time after completion of their treatment (Rogers et al., 2018). A pathological perspective has been the leading focus in HNC studies for many decades (Moorhouse and Edwards, 2018). However, focusing only on disease and problems often results in an incomplete understanding of a person's condition (Seligman and Csikszentmihalyi, 2000). A salutogenic focus concentrating on a person's strength and health resources has shown to be a significant factor in well-being and happiness (Antonovsky, 1996; Ventegodt et al., 2011). This attitude of positive psychology moves beyond the disease and supports the person's growth, providing conditions to balance problem-focused care (Seligman and Csikszentmihalyi, 2000). Csikszentmihalyi (1975) claims that where there is a requirement to enrich life, the flow theory is one way of achieving this.

HNC involves different types of malignant tumours in sinuses, nasal and oral cavities, the tongue, salivary glands and the larynx and pharynx; including the nasopharynx, oropharynx and hypopharynx (Rogers et al., 2018). The majority of HNC cases involve squamous cell carcinomas and adenocarcinoma (Isaksson et al., 2016). The 5-year survival rate is around $50 \%$, depending on tumour location, size, stage and age (Moorhouse and Edwards, 2018). $\mathrm{HNC}$ is most common in people aged $>50$ years and affects more than 5.5 million people globally (Global Burden of Disease Study [GBD], 2015). The annual incidence stands at about 4,500 in the Nordic countries, while specifically in Sweden around 1,200 people are affected (American Cancer Society, 2015; Swedish National Board of Health and Welfare, 2016). Twice as many men as women suffer from this disease. Another gender difference is that the risk of women suffering from thyroid cancer is three to four times higher than in men. Tonsil cancer has increased threefold in men since the 1970s and is linked to human papilloma virus infection of the mucosa (Haeggblom et al., 2017). HNC often begins with trivial complaints such as a blocked nose, sore throat, hoarseness, earache, mouth ulcers and swollen lymph glands. The symptoms often progress, causing problems in day-to-day life such as pain, bleeding, breathing difficulties, fatigue, nose or mouth odour, speech difficulties and difficulties with swallowing, besides changes in appearance (Isaksson et al., 2016). Such situations are difficult to handle, and optimistic or pessimistic thinking is related to psychosocial contemplations, previous and present experience and the ability to socialise (Humphris, 2016). This highlights the need to seek health resources and relief when dealing 
with this complex and serious disease (Midgley et al., 2018). Care and treatment for HNC need to follow recommendations from the European Society for Medical Oncology [ESMO] (2019) and the Clinical Practice Guidelines [CPG] (2019). In Sweden, the standard treatment pathway for HNC is based on a national healthcare programme that follows these recommendations. Care and treatment are based on clinical factors and the effects on the individual; that is, histological diagnosis, primary site, tumour size and spread. Treatments for HNC offer cure and/or palliation of various side effects, such as long-term changes when swallowing and/or communicating, causing psychosocial and existential problems (Moorhouse and Edwards, 2018). Concentrating on the individual's everyday life and how they act, think and feel daily, is pivotal; especially in view of the round-the-clock impact of the HNC on the people's day-to-day life and its improved survival rate (Isaksson et al., 2016).

\section{Flow theory}

Flow theory, which is rooted in positive psychology, focuses on positive experiences and ways to improve health and the functioning, performance and well-being of the individual (Seligman and Csikszentmihalyi, 2000). Flow theory comprises nine elements describing the mindset during optimal flow (Jackson and Csikszentmihalyi, 1999) (Table 1).

Table 1 Overview of the nine elements of optimal flow (Jackson and Csikszentmihalyi, 1999)

\begin{tabular}{|c|c|c|}
\hline Element & Component & Content \\
\hline Element 1 & Challenge- skills balancing & $\begin{array}{l}\text { A balance between the perceived challenges of the } \\
\text { activity and skills in handling problems and achieving } \\
\text { flow experiences }\end{array}$ \\
\hline Element 2 & Merging- action and awareness & $\begin{array}{l}\text { Being absorbed in the activity, being at one with the } \\
\text { activity, just doing the activity without thinking }\end{array}$ \\
\hline Element 3 & Clear goals setting & Clear personal goals, direct action, providing focus \\
\hline Element 4 & $\begin{array}{l}\text { Immediate feedback to one's } \\
\text { actions }\end{array}$ & $\begin{array}{l}\text { Direct feedback after achievements or letdowns, when } \\
\text { actions can be adjusted if necessary }\end{array}$ \\
\hline Element 5 & Concentrating on the task at hand & All attention is focused on an activity while doing it \\
\hline Element 6 & Sense of control & $\begin{array}{l}\text { Personal control or agency when dealing with matters } \\
\text { and being capable of completing tasks }\end{array}$ \\
\hline Element 7 & Self-consciousness disappearing & $\begin{array}{l}\text { Concern for the self disappears when in a flow state } \\
\text { worries and negative thoughts - for example - disappear }\end{array}$ \\
\hline
\end{tabular}


Flow experiences, theorised as holistic consciousness and defined as a state of mind of action, provide optimal flow and positively endow the individual's everyday values with pleasurable feelings (Csikszentmihalyi, 1998). There are different levels of flow, and optimal flow occurs when ordinary experiences are enhanced to an optimal level and positive feelings are in harmony with activities (Csikszentmihalyi, 1998). This state of focus and engagement is known to give people strength and intrinsic motivation (Seligman and Csikszentmihalyi, 2000). It is linked to achievements in creative activities that challenge and balance the individual's skills, e.g. when rock climbing or in higher education, generating a sense of personal improvement (Jackson and Csikszentmihalyi, 1999). Microflow is part of everyday life, with the lower level of complexity giving structure and reducing stress as described in six activities (Csikszentmihalyi, 1975) (Table 2).

Table 2 Overview of the six microflow activities (Csikszentmihalyi, 1975)

\begin{tabular}{|c|c|c|}
\hline Activities & Component & Content \\
\hline Activity 1 & Imagining & $\begin{array}{l}\text { Daydreaming, music in the head, talking to oneself, plants, pets, humming, } \\
\text { whistling or singing }\end{array}$ \\
\hline Activity 2 & Attending & $\begin{array}{l}\text { Watching people or things, watching TV, listening to the radio, reading } \\
\text { books or magazines }\end{array}$ \\
\hline Activity 3 & Oral & Snacking, smoking or chewing \\
\hline Activity 4 & Kinaesthetic & $\begin{array}{l}\text { Walking, pacing, running, small muscle movements, touching, rubbing, } \\
\text { playing games or doing sports alone }\end{array}$ \\
\hline Activity 5 & Creative & $\begin{array}{l}\text { Doing artwork, playing an instrument, working, sewing, writing a letter or } \\
\text { doodling }\end{array}$ \\
\hline Activity 6 & Social & $\begin{array}{l}\text { Browsing, shopping, talking and joking with others, social events, parties or } \\
\text { sexual activity }\end{array}$ \\
\hline
\end{tabular}


Studies such as Pálsdóttir et al., (2013) have focused on flow theory and its effects, studying flow during rehabilitation when people diagnosed with stress-related mental illness show that flow supports their ability to transform individual life values. This was demonstrated when people learned to adopt a more leisurely pace of everyday living, and activities were frequently related to nature and creativity (Pálsdóttir et al., 2013). For older people, participation in video games and innovative technology has shown to create flow (Glännfjord et al., 2016). Reynolds and Prior (2006) depicted women living with different cancer diagnoses who were involved in various art-making activities, and their flow experiences provided feelings of happiness. Furthermore, the study by Unruh and Elvin (2004) described women living with a breast cancer diagnosis and experiencing happiness during flow when joining in with dragon boat racing. In an HNC context, health-promoting experiences not unlike flow were identified when people were involved in hobbies or spending time outdoors (Björklund et al., 2008). Flow helps people to maintain their health regardless of illness according to a salutogenic approach (Antonovsky, 1996; Ventegodt et al., 2011). However, no study has been found describing flow theory in an HNC context. The purpose was therefore to describe flow as experienced by people diagnosed with and treated for HNC.

\section{Methods}

\section{Design}

As there was a lack of data regarding flow theory in an HNC context, a descriptive design with a qualitative approach was used in order to identify people's experiences in depth. The design was implemented as a deductive qualitative content analysis and used to explain Csikszentmihalyi's flow theory (Jackson and Csikszentmihalyi, 1999) through the perspective of everyday life with HNC.

\section{Participants}

Participants to the study were purposively selected (Fridlund and Hildingh, 2000) by the first author (MB) in consultation with medical and nursing staff involved in their care. To be included, participants had to have been diagnosed with HNC, be over 18 years of age, be able to understand and speak Swedish, and be willing to verbalise and communicate personal 
experiences. Nine people were given written information about participation during a clinical visit to a contact nurse. This information described the study and its purpose and gave them opportunity to accept or decline at any time. Seven people accepted (Table 3) and two declined, as they felt too ill to participate. Following oral informed consent, the contact nurse got in touch with the first author about potential participants and phoned them to ensure voluntary participation, integrity and confidentiality.

Table 3 Sociodemographic and clinical data of the participants diagnosed with and treated for head and neck cancer $(\mathrm{N}=7)$

\begin{tabular}{lllll}
\hline Diagnosis & Gender & Cohabital status & Age & Occupational status \\
\hline Cheek cancer & female & married & 64 & working \\
Laryngeal cancer & male & married & 74 & retired \\
Nasal cancer & female & divorced & 42 & working \\
Tongue cancer & male & married & 67 & retired \\
Tongue cancer & female & married & 73 & retired \\
Tonsil cancer & male & cohabiting & 62 & working \\
Tonsil cancer & male & married & 67 & retired \\
\hline
\end{tabular}

The participants had different HNC diagnoses. The cancer of two of the participants had not spread, while four experienced recurrence close to the first tumour and five had lymphatic gland metastasis. All participants were treated with surgery and radiation with curative intent, and three had additional chemotherapy. The time between diagnosis and the interview varied from two to ten years. Five of the participants had Swedish origins, and two were foreignborn. Four men (mean age 69.6) and three women (mean age 59.6) participated. All had children, and six had grandchildren.

\section{Data collection}

The first author conducted a one-off individual interview with each participant between September and November 2016. All interviews were conducted in calm, private places at the participants homes in southern Sweden, according to their own wishes. The interviews asked open-ended questions following a semi-structured interview guide drafted by the three authors (Fridlund and Hildingh, 2000) (Table 4). The authors had extensive experience of qualitative research methods, and the first author was familiar with the context through years of work 
experience in $\mathrm{HNC}$ care. Consensus about the interview guide was achieved following a pilot interview, which was performed after being considered relevant for the purpose of the study.

Table 4 Query guide for interview based on flow theory, aimed at participants diagnosed with and treated for head and neck cancer (Csikszentmihalyi, 1975)

\footnotetext{
Questions

Please tell me about your day-to-day life, from morning until bedtime.

Please tell me about a task that engaged and challenged you so much that you wanted to continue with it because it gave you pleasure or happiness.

Please tell me about a task that challenged you and boosted your self-confidence as you managed to do it.

Please tell me about a task which allowed you to focus and concentrate on something that you know about and gave you good feelings.

Please tell me about an activity that involved you so powerfully that you did not think about anything else, making it seem as though the world around you had disappeared.
}

The interview began with a discussion about sociodemographic data - age, family, diagnosis and treatment - which subsequently inspired confidence and instilled an atmosphere of trust. An open question was then posed, reflecting experiences of everyday life. The participants were given the opportunity to talk freely based on their needs. Probing questions and followup questions such as what happened; describe your feelings or experiences; anything more you want to add or express; is this what you mean, were used to uncover flow. Four interviews lasted about one hour, while three lasted over two hours.

The interviews were recorded digitally, and the participants spoke freely with a mobile phone recorder present, although they were asked to disregard it. All participants had speech difficulties, which meant that answers often had to be clarified in writing or through body language, e.g. using facial expressions or pointing to the body to describe worries or cheerfulness. The first author transcribed the interviews verbatim in the days that followed, as memory is dependent on a time factor. At that time, involvement during the interview situation was recalled and small notes were added to the transcripts to indicate what happened, where necessary; e.g. body language, gestures or episodes of coughing, crying or laughing.

\section{Data analysis}

Data was analysed using deductive qualitative content analysis, and the analysis process was divided into three phases: preparation, organisation and reporting (Elo et al., 2014). Literature 
on the flow theory (Jackson and Csikszentmihalyi, 1999; Csikszentmihalyi, 1998; 1975) was read carefully during the preparation phase. The first author listened carefully to the interviews, and the query guide provided sufficient and proper data. The interview text was read as open-mindedly as possible in order to gain a sense of the overall picture and formulate ideas for the deductive analysis. To minimize risk of bias due to preconceptions in the analysis, the first author engaged in writing memos of the meaning of what the participants were describing, having the flow theory and own preconceptions in mind. The text was processed, and statements related to flow experiences were identified. Watching for statements when the participant described how something special had triggered feelings of optimal flow was highlighted; this is because optimal flow enhances the ordinary to form optimal experiences when positive emotions are described as being in harmony during ongoing activities (Csikszentmihalyi, 1998). Microflows were identified as a lower level of complexity that provided structure in everyday life and quelled uneasiness. These modest structured activities seemed to fill the gaps in different everyday routines and helped the participants to focus on enjoyment; such as when humming, singing, reading books or listening to the radio. In the organisation phase, all experiences of flow were coded according to content and assigned to the nine elements of optimal flow and the six activities of microflow. Consequently, to ensure a reasoned interpretation, the identifications and descriptions of the nine elements and six activities were further critically analysed, reflected on and compared in relation to the purpose in focus, linking to the participant's everyday life and activities involved. It was noticeable that the elements and activities were easy to value: however, deciding where they belonged was problematic as some content seemed to fit in with more than one element or activity. All the authors discussed and evaluated the statements and disagreements were resolved by discussion until a negotiated consensus was reached. The final phase, reporting, comprised a description of the analysis following the results that were linked back to the literature. All the authors were involved in and collaborated on the entire analysis process. The results section provides quotations from all participants in order to describe their experiences of flow in their own words.

\section{Ethical considerations}

The study was approved by the Linköping University Ethics Committee (LI 40/31 2016). Chief physicians of the hospitals at which the participants were treated were also informed of and approved the study. One-on-one interviews were chosen accordingly as being the most 
appropriate way of gaining an understanding of people's everyday lives (Fridlund and Hildingh, 2000).

\section{Results}

The participants described a process when searching for happiness and positive things that helped them to overcome their worries. Their everyday lives were in disarray, and brief moments of happiness needed to be captured so that they could endure the problems caused by HNC and its treatment. They pushed their bodies to their limits of skill and endurance in order to manage complex situations or problems with eating, drinking and breathing. This was done through the participants' unique experiences and ideas of optimal flow, and they used mind resources and existential resources together with physical, technical and contextual components to find optimal flow. The process of finding optimal flow involved mental struggle and innovative reasoning that they integrated wholeheartedly in these enjoyable situations, resulting in happiness and good moods. This process of flow improved their skill levels, self-consciousness and self-care activities. Microflow involved habits creating feelings of pleasure that relieved stress and anxiety, such as listening to the radio, playing music, watching TV, talking to friends or daydreaming.

\section{Challenge- skills balancing}

The participants described optimal flow when matching their chances of meeting a challenge and attempting to create a balance in their day-to-day lives. Specific skills in terms of selfcontrol and a search for knowledge were developed to help them endure stressful circumstances. Belief in their own abilities to perform and act peaked and improved power and their control over their bodies and minds.

The sauna presents a challenge as regards my breathlessness, bronchitis, asthma and fatigue. However, inhaling the steam helps as it soothes my dry mouth, throat and lungs; I take a seat for a short while... my body and mind are in focus and things go very well... I feel comfortable and happy (P3)

Participants described ways of enhancing their inner capacity skills when experiencing stressful situations. They actively initiated an inner dialogue in regards to find strategies, watch TV or YouTube, or read books to learn more. This allowed them to deal with their 
restrictions in their own skills and how to perform these strategies in a different way. They depicted the microflow components imaging and attending by using spiritual thinking and daydreaming when lying in bed and listening to the radio or the sounds of nature.

When I feel miserable and extremely tired, I must be outdoors... it's lovely lying out in my conservatory, listening to the blackbirds or looking at the autumn colours and hearing the leaves falling (P4)

When me and my husband are going to sleep, we hold each other ... then I hear him cry and say... I love you that it hurts ... I have bad conscience because I'm so sick ... I close my eyes and pray to survive and think what is important tomorrow ... I choose sub-goals because I am so incredibly tired (P1)

\section{Merging action and awareness}

The participants described optimal flow during immense focus where the mind and body worked together. This involved awareness of creating good feelings and a mental challenge that required motivation and inner will - to be able to eat and drink, for example - giving greater self-confidence when successful.

Having no sense of taste is hard, but I've learned to concentrate and imagine how things tasted before my disease. When I'm outside the bakery or a pizzeria, I stand and sniff. When the smell makes me feel the food tastes as good as it smells, this makes me feel happy (P6)

Participants described the microflow activities imaging and kinaesthetic when daydreaming and walking in the forest. This corresponded to a sense of freedom, relief and inseparability with the activities.

I like to go walking in the forest, and it's wonderful to just think when I walk around searching for blueberries. It's as if my feelings just float freely (P3) 


\section{Clear goals setting}

The participants described optimal flow when achieving their own goals in ways that created a great sense of triumph and knowledge that formed self-confidence. They needed to define clear goals in advance and focus on what they could do and how to find happiness. They learned how to swallow and set short-term goals during tests involving foods of different consistencies. After attaining these goals, they set long-term goals for themselves; such as eating without the need of enteral nutritional assistance.

I decided to stop using the stomach tube and feed myself through my mouth. I still can't drink liquids or eat soup as they come up through my nose. I can't eat pureed food either, as it settles in the cavities in my mouth... I discovered that I could toss small bits of food into my mouth, back behind my tongue. It works well. I'm overjoyed that I got rid of the stomach tube, and this gave my selfconfidence a boost (P5)

The participants' main goals were holistic and focused on different approaches; but again, clear goals of surviving, better health, understanding the meaning of life and returning to a normal life were set, even though these were impossible since the progress of various cancers affected them in their day-to-day lives. They described microflow activities such as imagining and creative when talking about and arranging potted plants.

I'm not planning on dying, and I decided from the outset that I must think to the future... it's a struggle to get up out of bed... and I have to dust the window ledge... I feel so happy and peaceful inside when it's clean and the houseplants are doing well (P3)

\section{Immediate feedback to one's actions}

The participants described how optimal flow gave them immediate feelings of what was good or bad, which led to repeated activities and in turn improved their self-care, so bringing happiness. Feedback was critical to successful outcomes deriving from their bodies, minds, family, friends or environment. 
It takes me two hours to clean my prosthetic palate and fit it correctly. I must learn to do it myself... then I'll be able to speak and eat. I've survived, and my eagerness to learn to take care of myself gives me a sense of contentment. I could also appreciate eating at a restaurant if I do that $(\mathrm{P} 1)$

Participants described skilfulness and awareness of the value of an act and how it was linked with perfect performance. They described microflow activities such as kinaesthetic and creative, and these provided psychological growth, especially since these were created by themselves, and their relatives and friends loved the things and made use of them.

When I come up with the idea of creating something, I know how to do it perfectly and when I put my ideas into practice, I adjust. When dressing an armchair, for example... I change things and try to make it perfect... I don't stop until I feel deep down that it's perfectly okay... So I go all-in to get it finished, and afterwards I feel energetic and happy (P1)

I sew clothes and knit for my children, grandchildren and siblings ... they order what they want... I feel joy and it is so fun ... I continue to work with those affected with strokes ... we sit together and bake cakes ... it happens that someone suddenly stands up... I am so happy that I have made a difference for someone ... the cookies smell good and everyone has a taste ... (P1)

\section{Concentrating on the task at hand}

The participants described an optimal flow while they were completely absorbed in what they were doing, and they learned to exclude depressive thoughts and reflected on these together with friends. They talked and focused on religious beliefs, which gave them inner peace and hope for the future.

I sit in my classic car in the garage and just smell its scent... I feel proud and happy, and I think of my good friends who helped me do up the car... I feel as if I'm in car dealership heaven (P7) 
Participants described full concentration and tuning into the task shaping the microflow activities as imagining, attending, kinaesthetic and social. They described talking to and watching animals. Further, attending social events, focusing on tasks and maintaining concentration over a long period.

My rescue dog and I focus completely during training. He's obedient and alert, and I enjoy doing training sessions with him (P2)

\section{Sense of control}

The participants described optimal flow when doing something that interested them and helped them to develop and change things in their day-to-day lives. These activities required inner will, awareness, focus and contemplation. They depicted the mental challenge of consuming food and controlling their day-to-day lives with a high degree of security. This forced them to think healthy thoughts, and not about the bad things and difficulties in their lives.

We love to travel and decided not to wait for healthier times, so we did well planning and getting a medical certificate, medical support, prescriptions for medicines and nutritional drinks, assistance at airports, taxis and organised excursions. We put a lot of effort into gain control over the situation, and we were exhausted but pleased and genuinely happy afterwards (P4)

Depending on their habits, participants got involved in exercise such as walking, cycling or running and described a sensation of lightness, ignoring fatigue, pain or other difficulties. They described the microflow activities as imagining and attending, and they felt a sense of serenity and satisfaction if they succeeded in doing things.

I enjoy audio books and listen to detective stories. This helps me to forget my worries and compensates helps to relax me. It's so peaceful... I often listen before bedtime, because this helps me have a good night's sleep (P3) 


\section{Self-consciousness disappearing}

The participants described how they lose awareness of self and ego when they are completely involved in an action. When they learned how to achieve an optimal flow feeling, they were able to induce this state by means of conscious focus, with mind and body working together. They sought moments that gave them a sense of joy and did so repeatedly. These ofteninvolved activities linked to nature, where they performed activities that they enjoyed or just enjoyed being there. In these moments, they lost the self-consciousness that intervened between the self and the environment, when their self-awareness disappeared due to negative thoughts. They did something that they loved, that evoked happiness. During this process, which counteracted its purpose, they were exposed to a form of self-danger when they were enjoying relaxing with friends.

I was sad and felt sick, but my friend rented a cabin (in an area where there are a lot of bears), we went fishing and had a wonderful time out in the silence and beauty of the countryside. When we got home, the cabin owner asked whether I'd seen the man up on the bridge. We certainly had, but then she said there was a big bear behind us... It was weird that we completely forgot to watch out for the bears ... It was an exciting and enjoyable trip, and I felt restored and strong... (P6)

Participants described the microflow activities as attending, oral, kinaesthetic, creative and social. These activities were part of everyday activities when spending time with others, singing, playing and laughing. It was important to maintain their usual everyday routines, and they described a sense of happiness, as they were able to continue with these various microflow activities. This helped them to reduce their pondering on various problems in their day-to-day lives, which had changed. They claimed that when they performed some activities, they thought about activities bringing happiness. This sometimes affected their judgment, as they were not really focused on their everyday problems. This happened when they drank alcohol or spent too much time on activities they performed repeatedly because they enjoyed them. These behaviours were directly hazardous due to the life-threatening side effects of their treatment or the location of their tumours. 
Ifelt sad after I had surgery to remove the cancer in my tonsils, so I phoned my friends and we drank cognac and played cards as usual. We had lots of fun and laughed a lot. I was worried afterwards as I discovered that my throat was bleeding, but it calmed down after a few days (P7)

\section{Sense of time distorting}

The participants described optimal flow giving rise to happiness by using self-discipline and self-adjusting approaches that helped them to endure difficult treatment. In these situations, they used self-control to ignore distracting stimuli and speed up time, and this was done by concentrating on various intellectual activities such as counting to a hundred or daydreaming about happy times with family and friends. They needed self-control and mental skills to endure terrible and endless radiation treatments. These involved the use of individually tested protective face masks during the radiation when needed to have their heads bent back and forced to lie completely still during the treatment. Their throats were swollen because of the location of the tumour and the side effects of the treatment. They were unable to spit out the mucus that accumulated in the throat due to this position, and they were afraid of being suffocated by the mucus in the throat. They felt contented and happy when they managed to overcome their environment and endure problems.

Having radiation treatment was hard as I was afraid of phlegm getting stuck in my throat, I thought it'd choke me... but then I found time passes faster when I focus and dream of travelling and having fun with my family or friends... This gave me hope and peace of mind (P3)

Participants described the microflow activities as attending, oral, creative and social. These activities were common everyday activities focusing on creating art, doing crosswords and using the Internet and social media.

I watch video clips... It's interesting and time flies... I use FaceTime and talk to my grandchild in the UK. We laugh and have lots of fun together. I'm so happy I get to experience this on my mobile phone $(\mathrm{P} 2)$ 


\title{
Autotelic feeling
}

The participants described optimal flow during everyday activities such as exercising and sports, hobbies or working. It created feelings that made them choose these activities to help find inner happiness, and they did so repeatedly.

There are lots of student occupational therapists at my work, and it's a privilege to shadow them while they train... We have a laugh together and learn about care and work to promote health and improve patients' everyday activities (P1)

Participants described all six microflow activities when experiencing diverse natural phenomena and embracing different weathers such as falling rain or snow, or watching rainbows, the Northern Lights, sunrises and sunsets. Furthermore, praying and singing in a church choir gave a sense of inner peace and happiness.

\begin{abstract}
My life is dreadful, but I'm a believer and I have a praying room, where I always have candles lit in front of a picture of Saint Charbel... I focus and pray many times a day, and I feel peaceful and happy afterwards. When my friends ask me how I feel, I always say I'm fine. I believe this when I pay attention to my own words, and this gives me energy and a sense of contentment (P5)
\end{abstract}

\section{Discussion}

The purpose of this study was to describe flow as experienced by people diagnosed with and treated for HNC. The results show that experiences of flow were associated with the participants' interests, skill levels and actions involved. Focus, feedback and control enabled them to create feelings of happiness. It was important to maintain habits and daily activities in order to overcome new physical, mental, social and spiritual challenges with their HNC and its side effects. Two levels of flow emerged; optimal flow and microflow. All nine elements of optimal flow were found within the participants' responses, and the most frequently used were the components Challenge-skills balancing, Concentrating on the task at hand and Clear goals setting. They found it difficult to endure everyday living, described their choice of activities in terms of interests and enjoyed doing them. Their concentration on activities was intense because of their desire to cope with the challenges they faced, and their self- 
confidence was increased if they were successful. It is obvious that participants defined clear sub-goals in advance so that they could focus on positive things that gave them a sense of joy. Once this was achieved, a feeling of success and happy moments in life was evoked. This corresponds well to the study by Isaksson et al. (2016), which describes how people diagnosed with and treated for HNC strive to manage everyday activities by learning to find ways to endure what they are going through; as well as the study by Björklund (2012), which shows how people diagnosed with and treated for HNC find that activities promoting health shape their empowerment. Empowerment is strongly linked to holistic health and the maturing of people when they work through difficulties, promoting actions towards selfformulated goals (Nordenfelt, 1995).

The participants revealed that the activities they chose evoked feelings of happiness, helped them to block out disturbances from the surroundings and led them to believe in the future. They sometimes needed to endure difficulties such as pain during treatment or tumour growth, and this was when they used activities from the component Sense of time is distorting. They focused closely on activities they enjoyed, which resulted in them forgetting the time or getting the impression that time was moving more quickly or more slowly than in normal situations. Activities such as conscious thinking, listening to music or using social media were used to speed up or slow time. This corresponds closely to the study by Agarwal and Karahanna (2000), which describes the theory of cognitive absorption. This is defined as a state of deep involvement with software, involving the notion that time goes quickly when concentrating on something that is interesting and brings joy.

The participants' abilities and motivation to expand their knowledge and learn things during optimal flow generated happiness. This was expressed in the components Immediate feedback for one's action and Sense of controlling. In the case of immediate feedback, they learned to discover feelings of what was good or bad during activities, which helped them to achieve Sense of controlling when building self-care routines, also increasing their self-esteem and bringing meaning to their lives. They learned to be absorbed and retain greater focus when performing activities, and it helped them to ignore their problems as well as increasing their self-awareness, independence and self-control. Basch et al. (2016) point out that symptom management is intensified if person report symptoms and discuss how to handle them with clinicians. Personality and choice of coping mechanisms mirror concerns and the ability to deal with problems, boosting people's 'support from the inner voice' and allowing them to 
take control and believe in themselves; an important mental skill for developing confidence when mind and body are working together (Jackson and Csikszentmihalyi, 1999). The Patient Concerns Inventory (PCI-HN) (Rogers et al. 2018) seems to discover not only problems, but also personal views on how health is perceived, and appears to be useful in developing and adding questions about optimal flow and microflow.

This study reveals six microflow activities that were habits pursued spontaneously by the participants during a normal day, and performing these actions created a sense of happiness and reduced stress. Different microflow components were selected, depending on the individual's physical, psychosocial and spiritual mood and the condition of their health. Nature and the countryside were a huge source of happiness; and if they were able to choose to continue everyday habits such as walking, jogging or cycling, they did so and described a feeling of freedom when being outdoors. The microflow component kinaesthetic was used when continuing with sports and described how exercise was the easiest route to happiness. People diagnosed with and treated for HNC often exercised regularly in order to promote physical health, improve self-esteem and reduce stress and depression (Midgley et al., 2018). Continuing exercise during chemotherapy to treat breast cancer improves physical function and quality of life, which are known factors in increasing self-confidence and enabling patients to cope with treatment (Wengström et al., 2018). It is therefore important to implement tailored exercise activities as part of HNC care.

Participants revealed that when feeling extremely drained, both physically and mentally, they chose calmer activities such as the microflow component imagining daydreaming and thinking about happy days. This was often combined with the microflow component attending when reading books, watching TV and listening to the radio or music. These results tally with the study by Creswell (2017) regarding mindfulness and feelings of psychological well-being. There is a need for expertise in HNC care and training in counselling and relational psychology (Salander et al., 2016), particularly as there is a lack of knowledge about HNC and the psychological consequences, and psychological interventions have every chance of improving people's ability to feel happiness. The microflow component oral when snacking or chewing was seldom used on account of pain, trismus or an inability to chew.

The participants continued to use various everyday activities, and it was common for them to use the microflow component creativity. It helped them to get out of bed and start painting, 
sewing, baking, playing instruments or continuing working within their professions. Feelings of happiness and contentment were evoked when they performed these activities. Likewise, they experienced joy when giving away something that they had created themselves, or when they felt that others still needed their help or services. It is important to support the individual's own strategies and actions when adopting a positive and salutogenic approach. An action in relation to the microflow component creativity could be along the lines of an occupation or ordinary, familiar thing that they do every day; and this is known as one of the most straightforward ways to achieve happiness (Hasselkus, 2002). This is consistent with all the microflow components that form everyday living habits bringing structure and contentment and reducing stress (Csikszentmihalyi, 1975). la Cour et al. (2009) point out the importance for people living with advanced cancer, and for healthcare professionals searching for the support of various activities or actions as a way of engendering meaning and happiness during uncertain times.

This study shows that despite the diagnosis, symptoms and treatment of HNC, it was important for person to meet, talk to and laugh with family and friends. Social activities such as shopping and visiting cafés, galleries or theatres allowed them to experience flow that brought them happiness and meaning in their day-to-day lives. Spirituality was also significant for participants, helping in their recovery or allowing them to prepare for the ends of their lives. Spiritual stimulation, spending time with others and singing at church were one of the activities in the microflow component social. This corresponds to the study by Gray (2017), which stresses that it is important to consider individual's values and preferences and develop good working relationships with chaplains and local religious leaders, who are often the first person to notice mental health problems as well (Gray, 2017). Spiritual requests are not a standard component of HNC care, and a person-centred follow-up consultation helps to identify unmet needs and allow for suitable interventions to be implemented (Semple et al., 2017). People diagnosed with and treated for HNC are vulnerable and experience existential loneliness, particularly before and after treatment (Björklund, 2012). Harding and Moss (2018) state the importance of understanding the reasons why people diagnosed with and treated for HNC undergo psychological changes, either positive or negative. Reasons may include tumour size, treatments and social factors such as living closely together with family and friends. Therefore, it is important for healthcare professionals to use tools to detect vulnerable individuals who are diagnosed with and treated for $\mathrm{HNC}$ and who need psychosocial intervention. The experimental sampling method (ESM) is therefore useful as a 
way of detecting psychosocial difficulties and acting on reactions in day-to-day activities as well (Hektner et al., 2007).

\section{Methodological considerations}

A methodological evaluation is performed according to the degree of trustworthiness when qualitative methods are applied (Elo et al., 2014). Credibility was established by the selection of experiences from both men and women and the purposive variety of the participants. They were selected by a contact nurse who was familiar with people diagnosed with and treated for various forms of HNC: this was an advantage due to the ability of the nurse to identify appropriate participants who would be willing to communicate their experiences. The first author's profession as a nurse with extensive experience of and familiarity with HNC care facilitated the interviews. All participants had problems with talking due to the locations of their tumours and the treatment and side effects, and adequate time was given to them during interview in order to generate an air of confidence. The first author had no caregiver contact with the participants, which gave them more of an opportunity to be open and honest in the interview situation. Although the sample comprised seven participants, the purposive selection is considered varied in terms of gender, age and origin.

Dependability was assured by the fact that the same researcher - that is, the first author carried out all interviews and transcriptions. The query guide based on the flow theory was used with a view ensuring that all participants were asked the same general questions, to ensure data stability and facilitate comparison between the interviews. The interviews were recorded digitally, and transcripts and texts were reread during the analysis process, allowing all the authors to remain close to the content of the interview. The whole text was analysed thoroughly, and analysis steps described were followed strictly according to the qualitative content analysis described by Elo et al. (2014). All authors were involved and collaborated in the entire analysis process, confirming the trustworthiness and dependability of interpretations.

Confirmability was assured as this involved interview with seven participants diagnosed with and treated for HNC who communicated their experiences, allowing for depth in the analysis process. The small notes in the transcripts, e.g. when they experienced episodes of coughing, crying or laughing, were found to be valuable during the analysis, and this process created 
reliable results. Quotations were presented from everyone, making it possible to ensure confirmation when readers act as examiners. The first author's experiences as a nurse and extensive experience of and familiarity with HNC care and context may possibly have had an impact on the outcome; but familiarity with the culture and context reinforces the trustworthiness. This could be a bias when using qualitative research methods since the interviewer is an integral part of the process and final product. As Galdas (2017) highlights, this is not desirable. To minimize this risk, the researcher reflected on preconceptions and the dynamic relationship with the participants, having the deductive approach from the flow theory in focus during the interviews. Additionally, since the participants had speech difficulties, the interviewer needed to ask focused questions such as "could you please fill out for me and clarify" were particularly important as a precautionary measure not to misinterpret the answers from the participants. The co-authors' scrutiny of the analysis process helped to maintain awareness of possible influences on the results.

Transferability was considered credible if people suffering from other forms of cancer can see the use and benefit of using optimal flow or microflow in order to experience happiness. Due to limited prior knowledge in this field, a descriptive deductive design with a qualitative analysis was used to explain and grasp Csikszentmihalyi's flow theory through the perspective of everyday living with HNC.

\section{Implications}

These results showed the importance for healthcare professionals thinking systematicially and using tools to detect vulnerable individuals who require psychosocial intervention. People diagnosed with, and treated for, HNC have a desire continue with their day-to-day habits. Therefore, it is important to identify and use optimal flow and microflow components as strategies and standards in care plans that aim to increase health and happiness for these individuals. Research is recommended on optimal flow and microflow in everyday life using various health care instruments that can capture flow before, during and after treatment of HNC. The Experimental Sampling Method (ESM) is useful for detecting psychosocial difficulties as it is able to capture responses of how people manage their daily life and activities. It is critical to enquire about thoughts, moods, actions and situations on multiple occasions, for detecting psychosocial difficulties. This instrument could be suitable to be use together with the instrument previously developed use on patients with HNC, such as the 
Patient Concerns Inventory (PCI-HN).

\section{Conclusions}

This study provides information about the importance of retaining habits and day-to-day activities for people diagnosed with and treated for HNC. Attentive focus, feedback and control made it possible for them to use activities and skills to create feelings of happiness. This was linked to experiences when they succeeded in overcoming physical, mental, social and spiritual challenges in their day-to-day lives. Optimal flow occurred in a wide variety of social interactions: at home, at work and during leisure time with family, friends and animals. Microflow occurred when the participants were engaged in small, almost instinctive actions with an essential meaning. Inner thoughts, daydreams, creativity, hobbies and exercise were commonly used. Further research is needed in other healthcare areas to increase knowledge about optimal flow and micro-flow for people with other serious illness. In such a way, it is possible to increase awareness of the importance of using positive psychology and happiness in situations involving treatments that are difficult to endure.

\section{Contributions}

The three authors worked collectively on study design, data collection, data analysis and manuscript preparation.

\section{Declaration of interest}

The authors declare no conflict of interest. This research received no specific grants from funding agencies in the public, commercial or not-for-profit sectors.

\section{Acknowledgements}

We are grateful to the participants for generously sharing their experiences. Jönköping University, Sweden, the Swedish Nurses' Association and the Swedish Association of health Professionals support this study. 


\section{References}

Agarwal, R., Karahanna, K., 2000. Time flies when you're having fun: cognitive absorption and beliefs about information technology usage. MIS Q. 24, 665-694.

https://doi:10.2307/3250951.

https://pdfs.semanticscholar.org/cddc/febd1d9ff8e6d29b0f5b34c61f87040cc606.pdf.

(accessed on 27 May 2019).

American Cancer Society, 2015. Global Cancer facts \& figures, third ed.

https://www.cancer.org/content/dam/cancer-org/research/cancer-facts-and-statistics/globalcancer-facts-and-figures/global-cancer-facts-and-figures-3rd-edition.pdf (accessed on 27 May 2019).

Antonovsky, A., 1996. The salutogenic model as a theory to guide health promotion. Health. Promot. Int. 11, 11-18. http://www.salutare.ee/files/ettekanded/Salutogenees.pdf (accessed on 27 May 2019).

Basch, E., Deal, A.M., Kris, M.G., Scher, H.I., Hudis, C.A., Sabbatini, P., Rogak, L., Bennett, A.V., Dueck, A.C., Atkinson, T.M., Chou, J.F., Dulko, D., Sit, L., Barz, A., Novotny, P., Fruscione, M., Sloan, J.A., Schrag, D., 2016. Symptom monitoring with patient-reported outcomes during routine cancer treatment: a randomized controlled trial. J. Clin. Oncol. 34, $557-65$.

Björklund, M., Sarvimäki, A., Berg, A., 2008. Health promotion and empowerment from the perspective of individuals living with head and neck cancer. Eur. J. Oncol. Nurs. 12, 26-34.

Björklund, M., 2012. A health promotion perspective of living with head and neck cancer, in: Agulnik, M. (Eds.), Head and Neck Cancer. Intechopen. https://doi:10.5772/32303.

https://www.intechopen.com/books/head-and-neck-cancer/a-health-promotion-perspective-ofliving-with-head-and-neck-cancer (accessed on 27 May 2019).

CPG, 2019. ESMO Clinical practice guidelines: head and neck cancers.

https://www.esmo.org/Guidelines/Head-and-Neck-Cancers (accessed on 27 May 2019).

Creswell, J.D., 2017. Mindfulness interventions. Annu. Rev. Psychol. 68, 491-516.

https://www.annualreviews.org/doi/pdf/10.1146/annurev-psych-042716-051139 (accessed on 27 May 2019).

Csikszentmihalyi, M., 1975. Beyond boredom and anxiety: experiencing flow in work and play, twenty-fifth ed. Jossey-Bass, San Francisco.

Csikszentmihalyi, M., 1998. Finding flow: the psychology of engagement with everyday life. Basic Books, New York.

Elo, S., Kääriäinen, M., Kanste, O., Pölkki, T., Utriainen, K., Kyngäs H., 2014. Qualitative content analysis. A focus on trustworthiness. SAGE open. 4, 1-10. 
https://doi.org/10.1177/2158244014522633.

ESMO, 2019. Who we are: ESMO board and committees. https://www.esmo.org/AboutUs/Who-We-Are (accessed on 27 May 2019).

Fridlund, B., Hildingh, C., (Eds.) 2000. Qualitative research methods in the service of health. Studentlitteratur, Lund.

Galdas, P., 2017. Revisiting bias in qualitative research: reflections on its relationship with funding and impact. Int. J. Qual Methods. 16, 1-2.

https://doi.org/10.1177/1609406917748992.

GBD, 2015. Mortality and causes of death, collaborators. Global, regional, and national life expectancy, all-cause mortality, and cause-specific mortality for 249 causes of death, 19802015: a systematic analysis for the Global Burden of Disease Study 2015. Lancet. 388, 14591544. https://doi: 10.1016/s0140-6736(16)31012-1.

Glännfjord, F., Hemmingsson, H., Larsson Ranada, Å., 2016. Elderly people's perceptions of using Wii sports bowling - A qualitative study. Scand. J. Occup. Ther. 24, 329-338. http://dx.doi.org/10.1080/11038128.2016.1267259.

Gray, A.J., 2017. Reflections on the WPA position statement on spirituality and religion. Ment Health Relig Cult. 20, 552-557. https://doi.org/10.1080/13674676.2017.1377997.

Haeggblom, L., Ramqvist, T., Tommasino, M., Dalianis, T., Näsman, A., 2017. Time to change perspectives on HPV in oropharyngeal cancer. A systematic review of HPV prevalence per oropharyngeal sub-site the last 3 years. Papillomavirus. Res. 4, 1-11. http://dx.doi.org/10.1016/j.pvr.2017.05.002.

Harding, S., Moss, T.P., 2018. The impact of treatment for head and neck cancer on positive psychological change within a year of completing treatment. Int. J. Oral. Maxillofac. Surg. 47, 302-308. https://doi.org/10.1016/j.ijom.2017.07.023.

Hasselkus, B. R., (2002). The meaning of everyday occupation, second ed. Slack, Thorofare.

Hektner, J.M., Schmidt, J.A., Csikszentmihalyi, M., 2007. Experience sampling method measuring the quality of everyday life. SAGE Publishing, Los Angeles.

Humphris, G., 2016. Psychological management for head and neck cancer patients: United Kingdom National Multidisciplinary Guidelines. J. Laryngol. Otol. 130, 45-48. https://doi.org/10.1017/S0022215116000426.

Isaksson, I., Salander, P., Lillehorn, S., Laurell., G., 2016. Living an everyday life with head and neck cancer 2-2.5 years post-diagnosis - a qualitative prospective study of 56 patients. Soc. Sci. Med. 154, 54-61. https://doi.org/10.1016/j.socscimed.2016.02.031. 
Jackson, S.A., Csikszentmihalyi, M., 1999. Flow in sports. Human Kinetics, Champaign.

la Cour, K., Johannessen, H., Josephsson, A., 2009. Activity and meaning making in the everyday lives of people with advanced cancer. Palliat. Support Care. 7, 469-479.

https://doi.org/10.1017/S1478951509990472.

Midgley, A.W., Lowe, D., Levy, A.R., Mepani, V., Rogers, S.N., 2018. Exercise program design considerations for head and neck cancer survivors. Eur. Arch. Otorhinolaryngol, 275, 169-179. https://doi.org/10.1007/s00405-017-4760-z.

Moorhouse, T., Edwards, D., 2018. Head and neck cancer. InnovAiT. 11, 342-346. https://doi.org/10.1177/1755738018758495.

Nordenfelt, L., 1995. On the nature of health: an action-theoretic approach, second ed. Academic Publisher, Dordrecht Kluwer.

Pálsdóttir, A.A., Grahn, P., Persson, D., 2013. Changes in experienced value of everyday occupations after nature-based vocational rehabilitation. Scand. J. Occup. Ther. 21, 58-68. https://doi.org/10.3109/11038128.2013.832794.

Reynolds, F. \& Prior, S., 2006. Creative adventures and flow in art making: a qualitative study of women living with cancer. Br. J. Occup. Ther. 69, 255-262.

https://doi.org/10.1177/030802260606900603.

Rogers, S.N., Lowe, D., Lowies, C., Yeo, S.T., Allmark, C., Mcavery, D., Humphris, G.M., Robert Flavel, R., Semple, C., Thomas, S.J., Kanatas, A., 2018. Improving quality of life through the routine use of the patient concerns inventory for head and neck cancer patients: a cluster preference randomized controlled trial. BMC. Cancer. 18, 444.

https://doi.org/10.1186/s12885-018-4355-0.

Salander, P., Isaksson, I., Granström B., Laurell, G., 2016. Motives that head and neck cancer patients have for contacting a specialist nurse - an empirical study. J. Clin. Nurs. 25, 31603166. https://doi.org/10.1111/jocn.13283.

Seligman, M., Csikszentmihalyi, M., 2000. Positive psychology: an introduction. Am. Psychol. 55, 5-14. https://doi.org/10.1037/0003-066X.55.1.5.

Semple, C.J., Lannon, D., Qudairat, E., McCaughan, E., McCormac, R., 2017. Development and evaluation of a holistic surgical head and neck cancer post-treatment follow-up clinic using touchscreen technology - feasibility study. Eur. J. Cancer Care. 27, e12809. https://doi.org/10.1111/ecc.12809.

Swedish National Board of Health and Welfare, Swedish Cancer Statistic, 2016. http://www.socialstyrelsen.se/Lists/Artikelkatalog/Attachments/20787/2017-12-31.pdf (accessed on 27 May 2019). 
Unruh, A., Elvin, N., 2004. In the eye of the dragon: women's experience of breast cancer and the occupation of dragon boat racing. Can. J. Occup. Ther. 71, 138-49.

Ventegodt, S., Omar, H.A., Merrick, J., 2011. Quality of life as medicine: interventions that induce salutogenesis. A review of the literature. Soc. Indic. Res. 100, 415-433. https://doi.org/10.1007/s11205-010-9621-8.

Wengström, Y., Bolam, K.A., Mijwel, S., Sundberg, C.J., Backman, M., Browall, M., Norrbom, J., Rundqvist, H., 2017. Optitrain: a randomised controlled exercise trial for women with breast cancer undergoing chemotherapy. BMC. Cancer. 17, 100.

https://doi.org/10.1186/s12885-017-3079-x. 